\title{
Surgical treatment of a rare case of granular cell tumour of the cervical oesophagus
}

\author{
Jerzy Piecuch ${ }^{1}$, Maciej Wiewiora', Wojciech Latos $^{2}$ \\ 1Department of General and Bariatric Surgery and Emergency Medicine, Medical University of Silesia, Zabrze, Poland \\ 2Department of Internal Diseases, Angiology and Physical Medicine, Center for Laser Diagnostics and Therapy, Bytom, Poland
}

Videosurgery Miniinv 2013; 8 (2): 166-169

DOI: 10.5114/wiitm.2011.32819

\begin{abstract}
A female patient was operated upon due to cervical oesophageal stricture induced by a tumour located just below the throat. Local excision of the tumour and reconstruction of the oesophageal wall was performed using the pre-vertebral fascia due to the presence of extensive oesophageal mucosa damage. The patient also required temporary alimentation by the gastrostomy route due to swallowing disturbances. The oesophagram depicted a contrasting airway passage without any evidence of fistula and contrast medium leakage through the oesophageal lumen. Four months after the operation, the patient did not report any issue with oral intake. The postoperative histopathological and immunohistochemical examinations provided evidence of a granular cell tumour (GCT). We believe that local excision of the tumour should always be considered in cases of tumours located close to the throat because it is less invasive than partial resection of a GCT in the oesophagus or oesophagogastrectomy.
\end{abstract}

Key words: oesophagus, granular cell tumour, surgery.

\section{Introduction}

Granular cell tumour is a rare, usually benign neoplasm, first reported by Abrikossoff in 1926. This neoplasm can appear in various locations in the body, especially in the oral cavity, skin, subcutaneous tissue and breast $[1,2]$. The tumour rarely appears in the gastrointestinal tract.

The case of a woman treated surgically due to the presence of a granular cell tumour that was causing almost total occlusion of the cervical oesophagus is described.

\section{Case report}

A 46-year-old woman presented with a dysphagia caused by a tumour that almost completely occluded the cervical oesophagus. On admission, she could swallow only fluid or semi-fluid food. Body mass, height and body mass index were $56 \mathrm{~kg}, 160 \mathrm{~cm}$ and $21.9 \mathrm{~kg} / \mathrm{m}^{2}$, respectively. Swallowing problems had been occurring for about one year and increasing in frequency. During that time, body mass decreased by $12 \mathrm{~kg}$. Apart from nicotine addiction, there were no other predispositions or other accompanying pathologies. All laboratory tests were within normal limits. In 2005, the patient underwent cervical spine stabilization because of discopathy.

Barium study of the upper gastrointestinal tract revealed a critical stricture of the cervical oesophagus that was equivalent in length to two vertebral bodies. Contrast-enhanced computed tomography confirmed the presence of a soft-tissue mass with 
a smooth outline that intensified very weakly after the administration of contrast material, which merged with the oesophageal wall at the height of the sixth and seventh cervical vertebrae (Photo $1 \mathrm{~A}$ ). No infiltration into the trachea or other adjacent structures was found. There was no increase in the number of lymph nodes. The upper endoscopy revealed smooth stricture of the oesophagus lumen just below the upper pharyngeal sphincter, which did not allow the endoscope to pass. Two endoscopic biopsies of the tumour failed to establish the histological basis of the lesion. The biopsies obtained showed only colloid masses, macrophages and cells with thyrocyte morphology. No neoplastic cells were found.

The patient was scheduled for an operation, and was operated on under tracheal general anaesthesia. An incision was made in the left sternocleidomastoid muscle to access the cervical oesophagus. In the upper part of the oesophagus, just below the throat, there was a smooth, springy tumour of $4 \mathrm{~cm} \times 3 \mathrm{~cm} \times 2 \mathrm{~cm}$ in size (Photo $1 \mathrm{~B}$ ). The tumour was growing and circuitously encompassed the entire circumference of the oesophagus. A longitudinal incision past all layers of the oesophageal wall exposed the underlying tumour, which almost entirely obstructed the lumen. The oesophageal mucosa did not show any changes. The tumour was prepared and removed from the muscularis propria of the oesophagus with efforts to preserve the integrity of the mucosa. Nevertheless, while the tumour was being separated, a 2-cm length of the mucosa of the posterior oesophageal wall was damaged. The lesion site was closed with continuous sutures extending to the oesophageal lumen. The longitudinal incision created in the oesophageal wall was sutured with a single suture in order to maintain the continuity of the oesophageal mucosa (Photo $1 \mathrm{C}$ ). The damaged site was additionally covered with mobilized pre-vertebral fascia, which was stitched on with knot sutures extending up to the lower throat sphincter and oesophageal muscular layers. The histopathology and immunohistochemical stain (protein S-100+, CD 68+, Ki-67 1\%) revealed signs of a granular cell tumour. The tumour was excised with tumour-free margins and frozen for sectioning.

The early postoperative period continued without complications. The patient did not have a temperature, and the wound appeared to be healing by first intention. Parenteral nutrition was administered without any oral fluids or solid food. On the seventh day after the operation, an oesophagram performed with water-soluble contrast medium did not reveal stricture or contrast-medium leakage through the oesophageal lumen. However, during swallowing, a small amount of contrast medium seeped into the larynx and upper airways, causing choking and coughing (Photo 2 A). A decision was made to provide alimentation by the gastrostomy route. The gastrostomy was laparoscopy assisted. Laparoscopy feeding jejunostomy has also been reported previously [3]. The patient was then dismissed from the hospital. For 2 months, she was fed by gastrostomy. At that time, the patient felt well and did not report any problems with salivary swallowing. In the middle
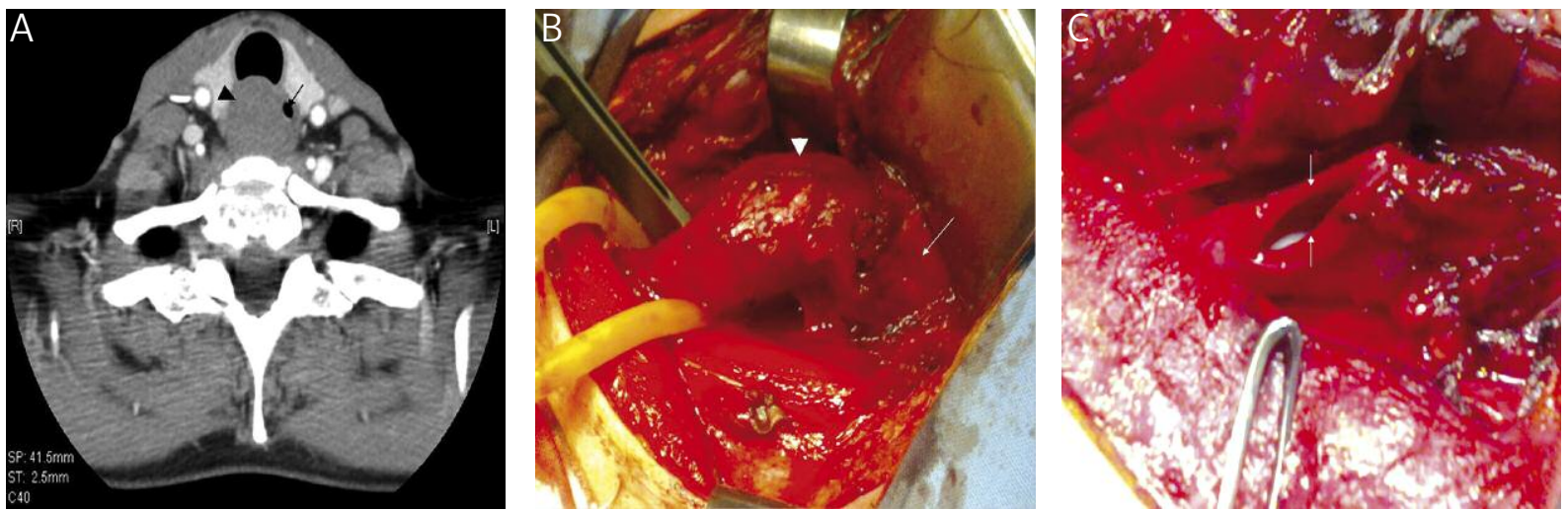

Photo 1. A - Contrast-enhanced CT demonstrated the presence of a soft-tissue mass encompassing the entire circumference of the oesophagus (black arrow - oesophageal lumen; black arrowhead - tumour). B - The upper oesophagus with an intramural tumour (white arrowhead) just below the pharynx (white arrow). C - Reconstruction of the continuity of the oesophageal mucosa through the use of a single suture. White arrow - the margins of the oesophageal mucosa 

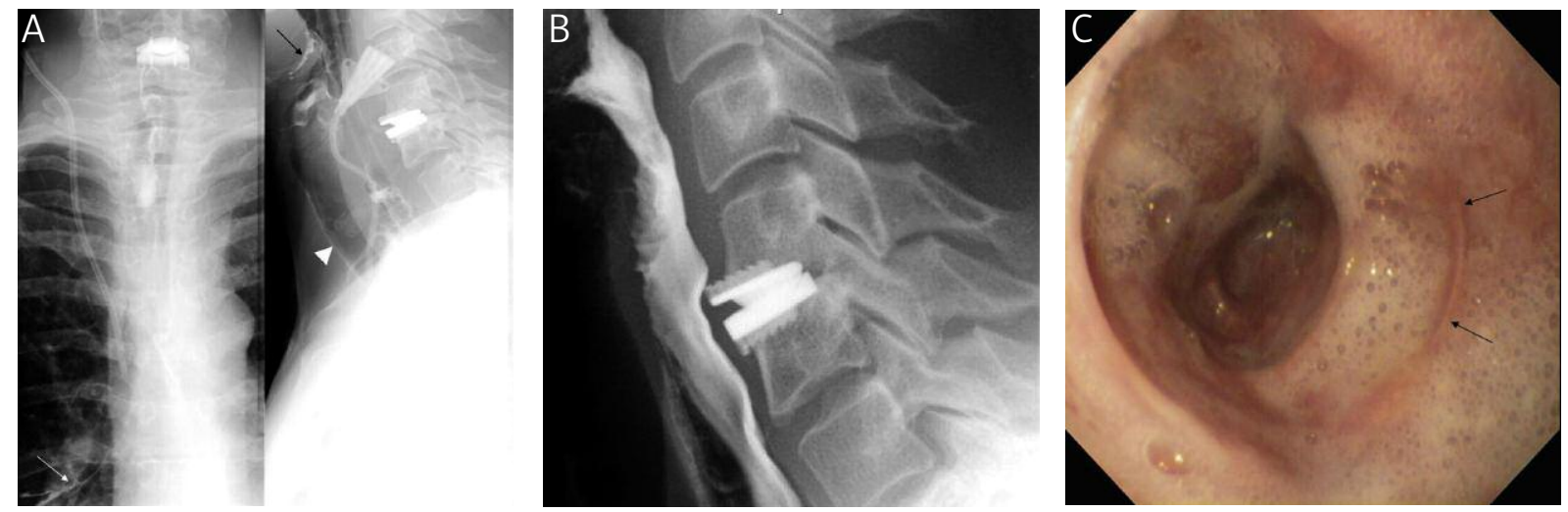

Photo 2. A - An oesophagram taken 7 days after the operation showed no stricture of the oesophageal lumen and the leakage of contrast medium into the larynx (black arrow), trachea (white arrowhead) and lower airways (white arrow). B - A normal oesophageal passageway 4 months after the operation. C - Upper endoscopy showed the presence of normal mucosa with a visible scar (black arrow) at the lesion site without signs of oesophageal stenosis

of the third month after creating the nutrition fistula, an oral fluid diet was introduced gradually, followed by solid food, which she tolerated very well. The control contrast examination of the upper part of the alimentary tract showed very slight contrast merging into the airway passage. She did not manifest any clinical problems with consuming food orally; she gained $5 \mathrm{~kg}$. The gastrostomy was removed 4 months after the operation after another contrast examination of the upper part of the alimentary tract, where a normal oesophageal passageway was found without any contrast in the airway passage (Photo 2 B). The results of control upper endoscopy were normal without signs of oesophageal stenosis. The mucosa at the site of the removed tumour was normal with a visible scar (Photo $2 \mathrm{C}$ ).

\section{Discussion}

The granular cell tumour (GCT) is a rare neoplasm that can occur in different parts of the body. Most tumours are benign, but a few become malignant and exhibit characteristic histological and immunohistochemical changes [4]. They usually form individual lesions, but several synchronic types have been reported [5]. Several reviews have found that only $1-8 \%$ of all GCTs occur in the gastrointestinal tract, mainly in the oesophagus. Of the various benign oesophageal tumours, $2 \%$ are GCTs. Among the GCTs, two thirds are lesions developing in the lower part of the oesophagus. These are usually asymptomatic [6].
The therapeutic management in a case of granular cell tumour of the oesophagus can include various therapeutic options. Small, asymptomatic tumours and tumours of confirmed non-malignant histological character can safely be observed [7]. Endoscopic excision is a safe and effective treatment method, especially for lesions with diameter smaller than $1-2 \mathrm{~cm}[8,9]$. However, symptomatic or growing tumours and those for which clear histological evaluations are not possible should be removed operatively, especially tumours larger than $2 \mathrm{~cm}$ in diameter, due to the risk of perforation during endoscopy [10].

The presented case of oesophagus granular cell tumour diagnosed using only postoperative histopathology and immunohistochemical staining is rather peculiar. First, the tumour was located in the cervical oesophagus below the throat, which is quite unusual. In the literature, only a few descriptions of granular cell tumours can be found in such locations [11-15]. In the list, which included 44 cases of granular cell tumour registered in Holland from 1988 to 1944, only 2 cases (5\%) were located in the neck [6]. Goldblum et al. described 13 patients with granular cell tumours of the oesophagus. Only one was located in the cervical region of the oesophagus; surgical excision was also necessary in one patient with a tumour $(2.5 \mathrm{~cm}$ in diameter) located just proximal to the gastroesophageal junction [16]. Second, we did not know the histological parameters of the tumour when planning the operation, which obviously affected the scope of the surgery. Most cases of GCTs can be diagnosed by endoscopic biopsy; however, a biopsy for histological 
diagnosis must be deep, because the lesions are located submucosally. In the case presented, the entirely closed oesophageal lumen prevented us from obtaining a reliable sample for microscopic examination. Third, the site and the circuitous tumour location, which was the cause of intraoperative problems, were of greatest importance in choosing a surgical procedure. There are several options for the management of oesophageal and thoracic disease. These include traditional options for treatment and operation through a minimally invasive approach [17-19]. We performed local excision of the tumour. In our opinion it is less invasive than partial resection of a GCT in the oesophagus or oesophagogastrectomy. During the operation, a long segment of mucosa was damaged. It was decided to recreate the oesophageal wall using the pre-vertebral fascia. Resection and reconstruction of the alimentary tract at this location would be very difficult and involve a serious risk of possible postoperative complications. Although the pre-vertebral fascia was partially scirrhous and difficult to separate from the foundation, it was mobilized sufficiently to cover the damage. Due to a potential risk of infection, the area of the disc-stabilizing implant was not prepared and remained untouched. Another report describes the interesting case of a young female patient, who underwent a partial resection of a GCT in the oesophagus and was then re-operated upon due to unfavourable postoperative results. These histopathological results demonstrated the aggressive nature of the tumour [11]. She was re-operated upon and underwent transhiatal oesophagogastrectomy, because two more GCTs were found in the proximal stomach. The postoperative period was complicated by an anastomotic leak on the neck. Fournier et al. have described a case of a granular cell tumour in the cervical oesophagus, where oesophageal excision and anastomosis were performed with a relocated stomach with no post-operative complications [15]. However, we believe that local excision of the tumour should always be considered in cases of tumours located close to the throat as opposed to tumours located distally, because the risk of surgical complications is definitely reduced in the latter case.

\section{References}

1. Morrison JG, Gray GF Jr, Dao AH, et al. Granular cell tumors. Am Surg 1987; 53: 156-60.

2. Billeret Lebranchu V. Granular cell tumor. Epidemiology of 263 cases. Arch Anat Cytol Pathol 1999; 47: 26-30.
3. Bobowicz M, Makarewicz W, Polec T, et al. Totally laparoscopic feeding jejunostomy - a technique modification. Videosurgery Miniinv 2011; 6: 256-60.

4. Rekhi B, Jambhekar NA. Morphologic spectrum, immunohistochemical analysis, and clinical features of a series of granular cell tumors of soft tissues: a study from a tertiary referral cancer center. Ann Diagn Pathol 2010; 14: 162-7.

5. Saleh H, El-Fakharany M, Frankle M. Multiple synchronous granular cell tumors involving the colon, appendix and mesentery: a case report and review of the literature. J Gastrointestin Liver Dis 2009; 18: 475-8.

6. Voskuil JH, van Dijk MM, Wagenaar SS, et al. Occurrence of esophageal granular cell tumors in the Netherlands between 1988 and 1994. Dig Dis Sci 2001; 46: 1610-4.

7. De Rezende L, Lucendo AJ, Alvarez-Argüelles H. Granular cell tumors of the esophagus: report of five cases and review of diagnostic and therapeutic techniques. Dis Esophagus 2007; 20: 436-43.

8. Zhong N, Katzka DA, Smyrk TC, et al. Endoscopic diagnosis and resection of esophageal granular cell tumors. Dis Esophagus 2011; 24: 538-43.

9. Lowe DL, Chaudhary AJ, Lee JR, et al. Four cases of patients with gastrointestinal granular cell tumors. South Med J 2007; 100: 298-300.

10. Schelling M, Hürlimann R, Uhlmann F. Electronic clinical challenges and images in Gl. Image 3. Granular cell tumor or Abrikossoff tumor of the esophagus. Gastroenterology 2009; 136: e7-8.

11. John BK, Dang NC, Hussain SA, et al. Multifocal granular cell tumor presenting as an esophageal stricture. J Gastrointest Cancer 2008; 39: 107-13.

12. Vuyk HD, Snow GB, Tiwari RM, et al. Granular cell tumor of the proximal esophagus. A rare disease. Cancer 1985; 15: 445-9.

13. Sarma DP, Rodriguez FH Jr, Deiparine EM, et al. Symptomatic granular cell tumor of the esophagus. I Surg Oncol 1986; 33: 246-9.

14. Sierra M, Sebag F, De Micco C, et al. Abrikossoff tumor of the proximal esophagus misdiagnosed as a thyroid nodule. Ann Chir 2006; 131: 219-21.

15. Fournier E, Salvan D, Lunggren MP, et al. Granular cell tumor of the cervical esophagus: a case report. Ann Otolaryngol Chir Cervicofac 2003; 120: 355-8.

16. Goldblum JR, Rice TW, Zuccaro G, et al. Granular cell tumors of the esophagus: a clinical and pathologic study of 13 cases. Ann Thorac Surg 1996; 62: 860-5.

17. Tarnowski W, Kiciak A, Borycka-Kiciak K, et al. Laparoscopic fundoplication improves oesophageal motility - a prospective study. Videosurgery Miniinv 2011; 6: 73-83.

18. Rembiasz K, Migaczewski M, Budzynski A, et al. Expression of cyclooxygenase- 2 in the mucosa of the gastroesophageal junction in patients with Barrett's oesophagus - the results of ablation therapy with argon plasma coagulation and laparoscopic Nissen fundoplication. Videosurgery Miniinv 2010; 5: 45-52.

19. Piwkowski C, Gabryel P, Kasprzyk M, et al. Video-assisted thoracic surgery pneumonectomy: the first case report in Poland. Videosurgery Miniinv 2012; 7: 197-201.

Received: 21.07.2012, revised: 17.10.2012, accepted: 3.11.2012. 